\title{
Transcriptome Profile Analysis Reveals the Regulation Mechanism of Stamen Abortion in Handeliodendron bodinieri
}

\author{
Xiatong Liu ${ }^{1,2,+}$, Tianfeng Liu ${ }^{3,+}$, Chong Zhang ${ }^{2}$, Xiaorui Guo ${ }^{2}$, Song Guo ${ }^{3}$, Hai Lu ${ }^{1,2} \mathbb{D}$, Hui Li ${ }^{1,2, * \mathbb{D}}$ \\ and Zailiu $\mathrm{Li}^{3, *}$
}

Citation: Liu, X.; Liu, T.; Zhang, C.; Guo, X.; Guo, S.; Lu, H.; Li, H.; Li, Z. Transcriptome Profile Analysis Reveals the Regulation Mechanism of Stamen Abortion in Handeliodendron bodinieri. Forests 2021, 12, 1071. https://doi.org/10.3390/f12081071

Academic Editors: Giovanni Emiliani and Alessio Giovannelli

Received: 9 June 2021

Accepted: 9 August 2021

Published: 11 August 2021

Publisher's Note: MDPI stays neutral with regard to jurisdictional claims in published maps and institutional affiliations.

Copyright: (c) 2021 by the authors. Licensee MDPI, Basel, Switzerland. This article is an open access article distributed under the terms and conditions of the Creative Commons Attribution (CC BY) license (https:/ / creativecommons.org/licenses/by/ $4.0 /)$.
1 Beijing Advanced Innovation Center for Tree Breeding by Molecular Design, Beijing Forestry University, Beijing 100083, China; summertong0621@sina.com (X.L.); luhai1974@bjfu.edu.cn (H.L.)

2 College of Biological Sciences and Biotechnology, Beijing Forestry University, Beijing 100083, China; chongzhang@bjfu.edu.cn (C.Z.); guoxiaorui0404@163.com (X.G.)

3 Forestry College, Guangxi University, Nanning 530004, China; 1tfltfll@163.com (T.L.); guos0@163.com (S.G.)

* Correspondence: 830lihui@163.com (H.L.); lizailiu666@163.com (Z.L.)

+ These authors contributed equally to this work.

\begin{abstract}
Handeliodendron bodinieri has unisexual flowers with aborted stamens in female trees, which can be used to study unisexual flower development in tree species. To elucidate the molecular mechanism of stamen abortion underlying sex differentiation, the stage of stamen abortion was determined by semi-thin sections; results showed that stamen abortion occurred in stage 6 during anther development. In addition, differentially expressed transcripts regulating stamen abortion were identified by comparing the transcriptome of female flowers and male flowers with RNA-seq technique. The results showed that 14 genes related to anther development and meiosis such as HbGPAT, HbAMS, HbLAP5, HbLAP3, and HbTES were down-regulated, and HbML5 was upregulated. Therefore, this information will provide a theoretical foundation for the conservation, breeding, scientific research, and application of Handeliodendron bodinieri.
\end{abstract}

Keywords: endangered plant; Handeliodendron bodinieri; stamen abortion; anther; pollen; meiosis

\section{Introduction}

Handeliodendron bodinieri, commonly known as Platycladus and Platanus, is a deciduous plant belonging to Sapindaceae and Handeliodendron Rehd. It is an endangered species endemic to the karst forest of southwest China. This plant has extensive application value in bio-energy, landscaping, and water and soil conservation fields. The flowers of $H$. bodinieri are unisexual with an aborted stamen or pistil in dioecious trees. Due to the unique features of $H$. bodinieri flowers, they can be used as perfect specimens to study sex differentiation and unisexual flower development in tree species.

Anther and pollen development is a complex biological process that includes a series of crucial events requiring cooperative interactions between gametophytic and sporophytic genes [1-5]. Timely release of the functional pollen is critical to seed formation and successful breeding [6]. In plants, anther development has been well studied. When the floral structures have successively generated, anther cells begin to differentiate and form four lobes. Then, archesporial cells are differentiated in each lobe [5,7]. The entire anther development process had been divided into two general phases: cell differentiation phase (cell specification tissue differentiation, meiosis, and spore formation), and degeneration phase (pollen grain and sperm cell differentiation, anther enlargement, filament extension, tissue degeneration, dehiscence, and pollen release) [1]. Sander et al. then divided the anther development of Arabidopsis thaliana into 14 stages based on morphological landmarks that correspond to cellular events visible under a microscope [8].

Male fertility in flowering plants depends on proper cellular differentiation in anthers. Plant male sterility manifestations are diversified, often showing as malformation, atrophy, or 
disappearance of anthers. Much research is focused on the abnormal development of anthers, such as microsporogenesis tissues formation failure [9], abnormal microspore formation [10], abnormal pollen or pollen abortion [11], and non-cracking anthers [12]. The meiosis process of microspore mother cells and tapetum development are fundamental processes in pollen formation. Many genes are preferentially expressed during male meiosis, indicating that the male meiotic cell cycle is genetically regulated by a complex network [13-15]. Tapetum is the innermost cell layer in the anther, in direct contact with the developing gametophytes [16]. Tapetum plays a vital secretory role in developing microspores to pollen grains by providing enzymes for the release of microspores from tetrads and nutrients for pollen and pollen wall development [1]. Generally, tapetum development can be classified into three stages: tapetum specification, tapetal cell binucleation, and degeneration through programmed cell death (PCD) [3]. Defective tapetum development is often associated with the disrupted development of pollen and impaired male fertility [17-19]. Moreover, many studies indicated that meiosis progression and tetrad formation are not merely regulated by the expression of genes within the mother microspore cell, but also involve the specification of tapetum and PCD of tapetal cells [20-22].

The flowers of $H$. bodinieri are unisexual and zygomorphic [23]. The pollen of typically developing stamens in the male flower undergoes sporogenous cell differentiation, microspore mother cell meiosis and formation, and pollen maturation [23]. However, the questions of which stage of pollen development that stamen begin to abort in female flowers and why anther development is degenerate had not been researched.

This study characterized different development processes of stamens in male and female flowers in $H$. bodinieri by semi-thin section. The stamen was aborted at stage 6 during anther development. RNA-seq was also used to compare key genes during different anthers' developmental stages in male and female flowers. Our results indicate that abnormal development of the anther tapetum and abnormal meiosis of the microspore mother cells initiate the abortion of stamen in H. bodinieri.

\section{Material and Methods}

\subsection{Plant Materials}

The H. bodinieri flowers were harvested in the limestone area around Meijia Mountain Villa in Leye County, Baise City, Guangxi Zhuang Autonomous Region. The flowers were collected from March to April 2017. Several male and female inflorescences or single flowers were randomly selected, which keep or remove the petals and receptacles in different directions and heights of each plant (with a height difference of more than $10 \mathrm{~cm}$ ). Fifty closed floral buds of different sizes were randomly picked and the flower sizes and diameters were measured with a digital vernier caliper. Male and female flowers with bud diameter less than $1.3 \mathrm{~cm}(\mathrm{X} 0$ and $\mathrm{C} 0)$, with bud diameter between approximately 1.3 and $1.6 \mathrm{~cm}(\mathrm{X} 1$ and $\mathrm{C} 1)$, and with bud diameter greater than $1.6 \mathrm{~cm}(\mathrm{X} 2$ and $\mathrm{C} 2)$, were separately collected from the same plant and used for transcriptome sequencing. Three biological replicates were analyzed for each sample counted as one replicate.

\subsection{Semi-Thin Sections}

Male and female flower buds were fixed in formaldehyde-acetic acid-ethanol fixative (FAA). The samples were then dehydrated in an alcohol gradient series $(50 \%, 70 \%, 95 \%$, and $100 \%$ alcohol; $30 \mathrm{~min}$ each step). The ethanol was then gradually replaced by propylene oxide ( $25 \%, 50 \%, 75 \%$, and $100 \% ; 10$ min each step) and samples were embedded in resin at $60{ }^{\circ} \mathrm{C}$ for $24 \mathrm{~h}$. Then, semi-thin $(0.2 \mu \mathrm{m})$ sections were obtained using an automatic microtome (Microm HM 360, Thermo Fisher Scientific, Waltham, MA, USA). The sections were stained with $0.1 \%$ toluidine blue $\mathrm{O}$ for $30-60 \mathrm{~s}$ at room temperature and observed with a Nikon Eclipse 80i microscope (Nikon, Tokyo, Japan). Images of the anthers in different stages were captured with a Nikon DS-Ri1 camera (Nikon, Tokyo, Japan). 


\subsection{RNA-Seq and Analysis of Sequencing Results}

Total RNA was isolated from samples using TRIzol reagent according to the manufacturer's protocol (Invitrogen, Carlsbad, CA, USA). After confirmation of RNA quality, the samples were sequenced using a BGISEQ-500 Analyzer (BGI Genomics, Shenzhen, China). Clean reads were obtained from raw data by filtering the adaptor sequences and the low-quality sequences using SOAPnoke. Then, the pair-end clean reads were de novo assembled into contigs by Trinity [24]. After that, TGICL tools were used to obtain the non-redundant unigenes [25]. Clean reads were compared to unigenes using Bowtie2, and gene expression levels of each sample were calculated using RSEM. Functional annotation of unigenes was performed by using homology-based searches (BLASTX), searches against the NT, NR, Swiss-Prot KOG, and KEGG databases. The GO annotations for the unigenes were determined using Blast2GO [26]. The data are deposited in the National Center for Biotechnology Information Gene Expression Omnibus database (https: / / www.ncbi.nlm.nih.gov / geo / query / acc.cgi?acc=GSE181240, accessed on 6 August 2021) under accession number GSE181240.

\subsection{Screening and Analysis of Differentially Expressed Transcripts}

TBtools was used to identify differentially expressed transcripts [27]; A corrected $p$-value of $<0.05$ and a $\log 2$ ratio $\geq 1$ or $\leq-1$ were set as the thresholds for significant differential expression between the two samples. Heatmaps were performed using TBtools software [27]. Gene ontology (GO) enrichment analyses of the differentially expressed transcripts pathways were performed using the OMICSHARE online tools (https:/ / www. omicshare.com/tools/home/report/goenrich.html, accessed on 1 February 2021). GO terms with a corrected $p$-value of $<0.05$ were considered significantly enriched among differentially expressed transcripts.

\section{Results}

\subsection{Growth Characteristics of Female and Male Flowers of Handeliodendron Bodinieri}

The inflorescence of $H$. bodinieri is a thyrse (Figure 1A,B). The flower blooms once a year, and its blooming time lasts from late April to mid-to-late May. Each flower usually has five sepals, four or five petals, and seven or eight stamens (Figure 1). From the perspective of a single flower, the flowering process follows four stages from floral buds sprouting, white appearing, petal spreading to full bloom, which takes $4-5$ days (Figure 1C,E). Here, the day of floral buds sprouting was set as the first day of the flowering process. On the second day, orange anthers (male flowers) or white stigma (female flowers) gradually grew out from the buds. On the third and fourth days, in male and female flowers, the petals spread and curled toward the receptacle. In the male flowers, the filaments elongated and the color of the anthers turned orange-red, followed by pollen release. In female flowers, the pistil elongated, and the development of stamens entered a stasis period. After that, in male flowers, the anthers turned brown, and the filaments turned red. In female flowers, the top of the stigma turned brown. The petals of both male and female flowers turned red from the base and then turned red completely (Figure 1C,E). For male flowers, the stamens developed normally, and the ovary was small and eventually degenerated (Figure 1D). On the contrary, in the female flowers, the pistil developed normally, and it was accompanied by an obvious stamen abortion (Figure 1F).

\subsection{Stamen Abortion Started at Stage 6 of Anther Development in H. bodinieri}

To further understand the mechanism of the stamen abortion in female flowers, the anthers were collected from male and female flowers at different stages of development. Then, the semi-thin anther sections were examined by microscopy. The results show that the development processes of male flower anthers in H. bodinieri and Arabidopsis were similar. Therefore, the development of $H$. bodinieri anthers was also divided into 14 stages using the anther development process of Arabidopsis [8] as a reference. 

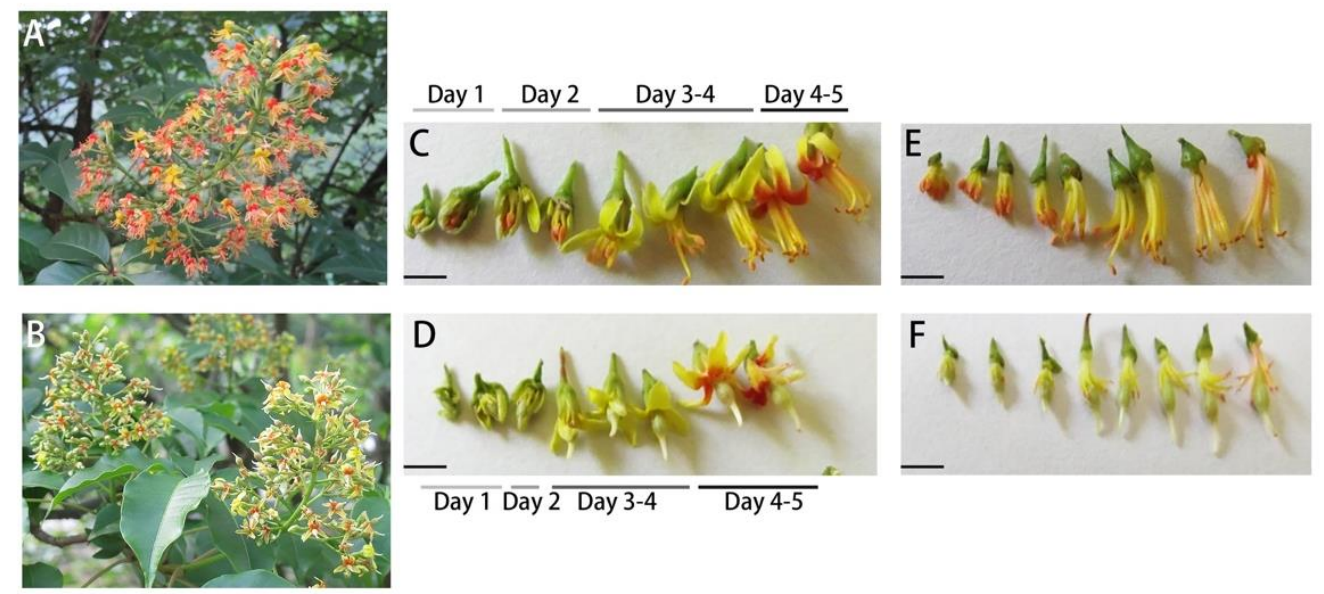

Figure 1. Phenotypic characterization of female and male flowers and floral buds. (A,B) The phenotype of male (A) and female (B) plants of H. bodinieri. (C-F) The phenotype of male (C,E) and female (D,F) floral buds of H. bodinieri, (E-F) only stamens and pistils remain. Scale bars indicate $5 \mathrm{~mm}$ in $(\mathbf{C}-\mathbf{F})$.

During stages 2 through 5, all types of anther cells were present, the pattern of the anther was defined, microspore mother cells (MMCs) appeared, and dense chromatin in some MMCs could be seen in both male and female anthers. No differences were observed between the male and female flower anthers in these stages (Figure $2 \mathrm{~A}-\mathrm{D}, \mathrm{H}-\mathrm{K}$ ). At stage 6 of anther development in the male flowers, the middle layer was crushed and degenerated, tapetal cells became vacuolated, MMCs entered meiosis, and the chromatin showed different forms during meiosis (Figure 2L). Finally, meiosis was completed, tetrads of microspores were generated within each locule, and tapetal cells became larger and contained dense cytoplasm (Figure 2M). However, in the female flower anther, abnormal, large vacuoles appeared in the tapetal cells, the chromatin of multiple MMCs was sparse, and the chromatids were scattered (Figure 2E). Additionally, in the female flower anther, MMCs failed to undergo meiosis and even started to degenerate, tapetal cells became larger, and they showed almost free of other components except for a large vacuole (Figure $2 \mathrm{~F}$ ). The size of the anther was significantly small at stages 8-9 in female flower anthers, and many tissues degenerated together while the tapetal cells remained turgid (Figure 2G). During stages 8-9 in the male flower anther, the callose wall surrounding the tetrads degenerated, and individual microspores were released from the tetrads, generated an exine wall, and became vacuolated, after which growth and expansion of the anther continued (Figure $2 \mathrm{~N}$ ). These results indicated that the female flower anther began abortion at stage 6 . In the process, the MMCs were unable to undergo meiosis to form pollen, and the tapetum of anthers could not develop normally.

\subsection{Changes in Gene Expression during the Male and Female Flower Development}

To elucidate the molecular mechanism that resulted in the abortion of female flower stamen, the male $(X)$ and female $(C)$ flowers at stage 3-5 (X0, C0), stage 6-7 (X1, C1), and stage 8-9 (X2, C2), were RNA sequenced. A total of 123,236 transcripts were obtained, of which 61,260 transcripts were successfully annotated by homologous annotation. Furthermore, 296 of them were found to be related to anther development. To analyze the expression pattern of male flower anthers in H. bodinieri, 12,706 transcripts were identified with significantly different expression levels (fold change $>2$ or $<-2$, corrected $p$-value $<0.05$, fragments per Kilobase of transcript per Million mapped reads [FPKM] $>5$ in at least one of three samples) in at least one of the time points from the buds of the male flower (X1 vs. X0, X2 vs. X1, X2 vs. X0) (Figure 3A). A total of 9635 transcripts with significantly different expression levels between male and female floral buds were identified for three time points (C0 vs. X0, C1 vs. X1, C2 vs. X2) (Figure 3B). 
A

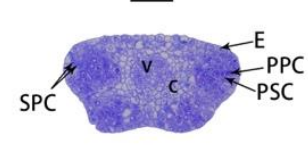

B

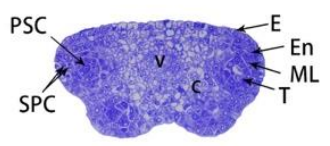

C

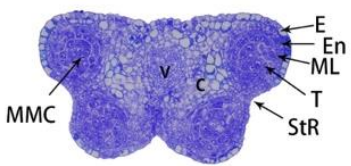

D

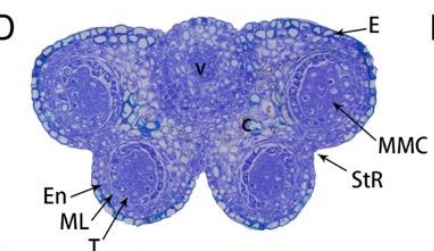

E

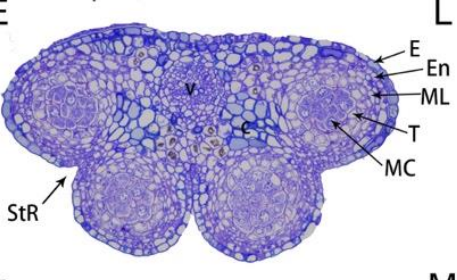

F

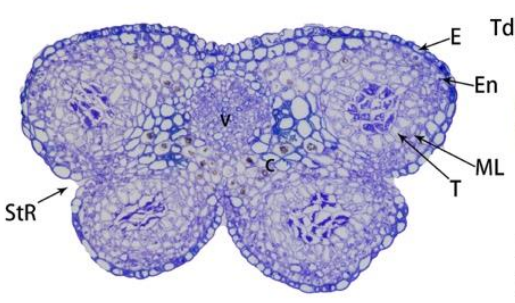

M

G

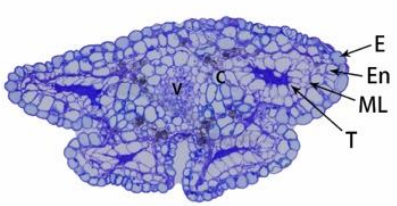

$\mathrm{H}$

I

M

$\mathrm{N}$
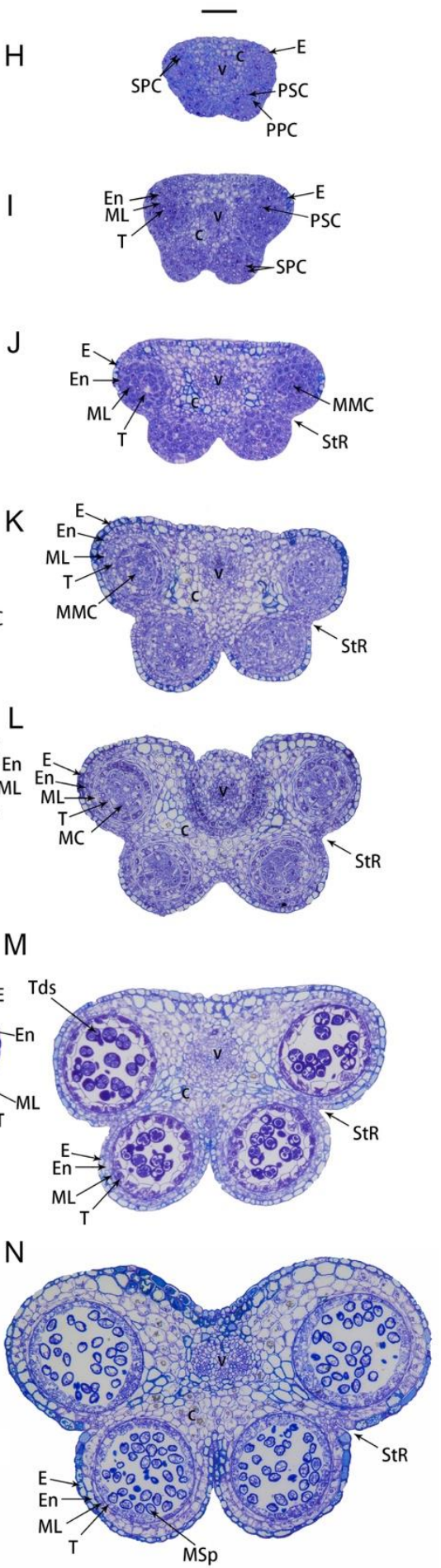

Figure 2. Cytological observation of anthers in female $(\mathbf{A}-\mathbf{G})$ and male $(\mathbf{H}-\mathbf{N})$ flowers by developmental. stage. (A,H) stage 3; (B,I) stage 4; (C,J) stage 5; (D,K) stages 5-6; (E,L) stage 6; (F,M) stage 7; (G,N) stages 8-9. Bars indicate $40 \mu \mathrm{m}$ for all the stages. E, epidermis; En, endothecium; SPC, secondary parietal cell; PPC, primary parietal cell; PSC, primary sporogenous cell; En, endothecium; $\mathrm{ML}$, middle layer; $\mathrm{T}$, tapetum; $\mathrm{StR}$, stomium region; $\mathrm{MMC}$, microspore mother cells; $\mathrm{MC}$, meiotic cell; Tds, tetrads; MSp, microspores; V, vascular region; C, connective. 
A
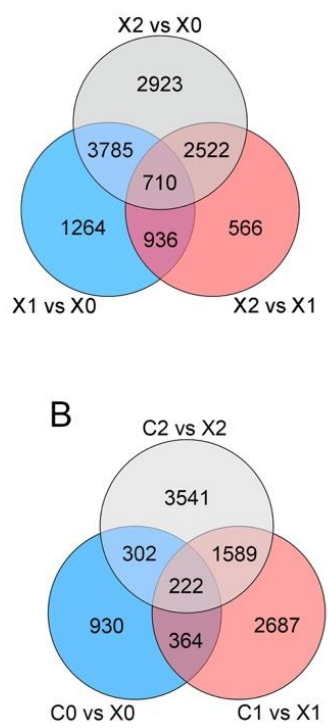

C
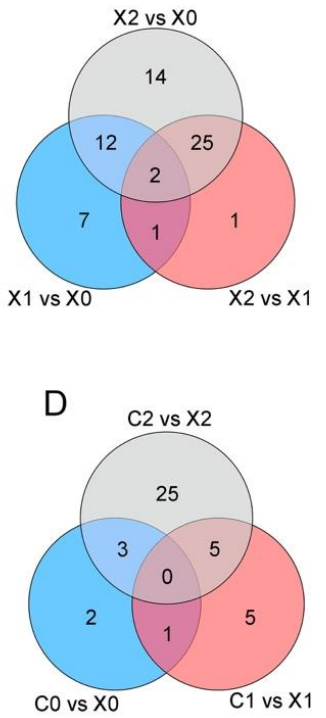

E

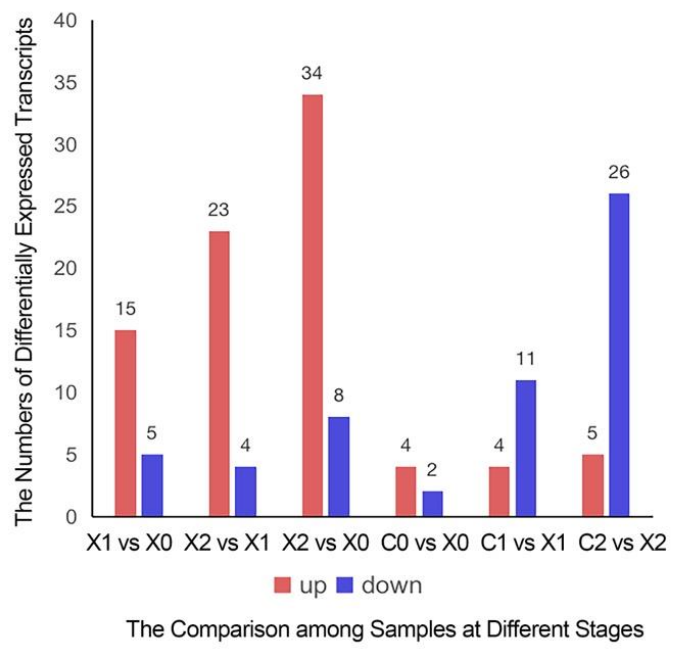

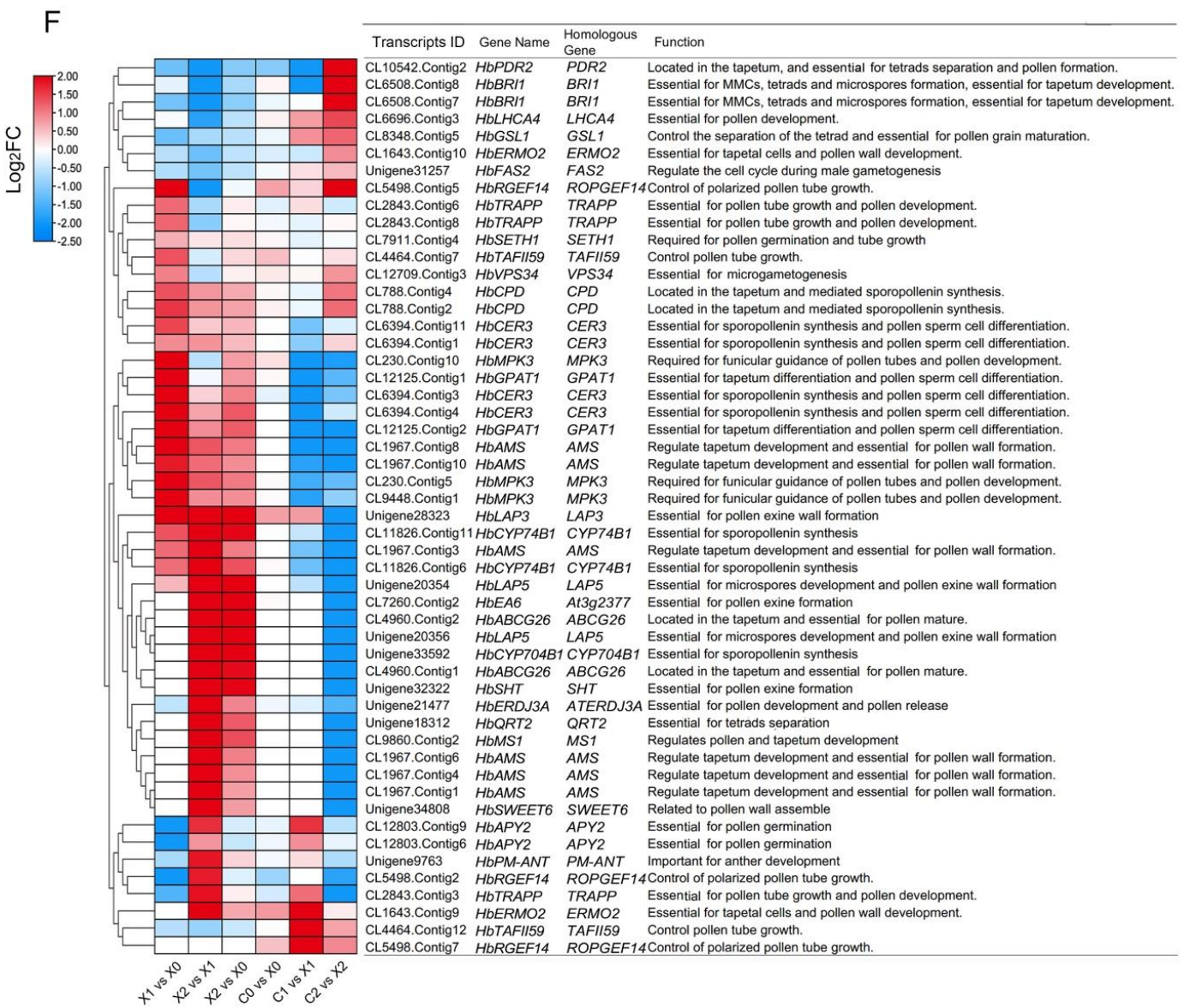

Figure 3. Analysis of the differentially expressed transcripts in male and female floral buds. (A,C) Numbers of the differentially expressed transcripts in male flowers; all transcriptome and anther development-related genes. (B,D) Numbers of the differentially expressed transcripts in female flowers; all transcriptome and anther-related genes compared with male flowers (E) Numbers of the up-regulated and down-regulated differentially expressed transcripts in male and female flowers' anther-related genes. (F) log2-transformed fold change $(\log 2 \mathrm{FC})$ values are depicted by color range from blue (down-regulated) to red (up-regulated). Slashes represent a pairwise comparison between two samples. Bar plots show the value. 
Among 296 transcripts involved in anther development that had been studied, 49 transcripts were detected with significantly different expression levels in at least one of the three time points from the male flower buds (Figure 3C). Of them, 15 were up-regulated in $X 1$ vs. $X 0,23$ were up-regulated in $X 2$ vs. $X 1$, and 34 were up-regulated in $X 2$ vs. $X 0$ (Figure 3E). Up-regulated in all stages were: $H b G P A T 1, H b C P D$, and $H b A M S$, essential for anther wall tapetum development; HbCER3, HbCYP74B1, HbLAP3, and HbLAP5, essential for sporopollenin synthesis and pollen exine wall formation; $H b M P K 3$, essential for pollen tube growth. HbVPS34, which is essential for microgametogenesis, was up-regulated in X1 vs. X0. HbTRAPP, HbTAFII59, and HbRGEF14, necessary for pollen tube development, were also up-regulated in X1 vs. X0. HbMS1, HbERMO2, HbSWEET6, HbEA6, and HbSHT, necessary for pollen exine wall development, were up-regulated in $\mathrm{X} 2$ when compared to $\mathrm{X} 1$. $H b Q R T 2$, required for tetrads separation, $H b A B C G 26$ and $H b E R D J 3 A$, required for pollen maturation, were also up-regulated in $\mathrm{X} 2$ compared to $\mathrm{X} 1$.

To further explore the key genes that regulated the abortion of female flower stamen, the expression of the 296 transcripts related to anthers' development were compared between male and female flowers at different stages. Thirty-eight transcripts were detected with significantly different expression levels from comparative tree groups (Figure 3D). In female flowers, 2, 11, and 26 transcripts were down-regulated at stages 3-5, stages 6-7, and stages $8-9$, respectively (Figure 3E). The $\log _{2}$ Fold Change value of all 52 different expressed transcripts detected from these six contrast groups ( $\mathrm{X} 1 \mathrm{vs} . \mathrm{X} 0, \mathrm{X} 2 \mathrm{vs} . \mathrm{X} 1, \mathrm{X} 2$ vs. $\mathrm{X} 0, \mathrm{C} 0$ vs. $\mathrm{X} 0, \mathrm{C} 1$ vs. $\mathrm{X} 1, \mathrm{C} 2$ vs. $\mathrm{X} 2$ ) was calculated to test the expression levels changes; the results are shown as a heatmap in Figure 3F. A detailed description of the differentially expressed transcripts is provided behind the transcripts ID (Figure 3F). HbCER3, HbCYP704B1, HbGPAT1, HbAMS, and HbMPK3 began to up-regulate in male flowers at stages 6-7. During the same stage, compared with male flowers, they were down-regulated in female flowers. HbLAP3 and HbLAP5 began to up-regulate in male flowers at stages 6-7. However, they were down-regulated in female flowers at stages 8-9. HbQRT2, HbMS1, $H b A B C G 26, H b E R D J 3 A, H b E A 6$, HbSHT, and HbSWEET6 were up-regulated in male flowers at stages 8-9, and down-regulated in female flowers at the same stage. There were two genes, $H b P D R 2$ and $H b B R I 1$, down-regulated in male flowers over time. Compared with male flowers, they were also down-regulated in female flowers at the same stage. These results indicate that the genes required for tapetum development, tetrads separation, and pollen formation mentioned above are down-regulated in female flowers, whose stamens were aborted.

\subsection{Changes in Gene Expression during the Male and Female Anthers Development}

To further prove the previous analysis and reduce the interference from tissues in male and female flowers, the transcriptomes of male and female flower anthers (a) were analyzed in groups of two developmental stages: stages 6-7 (1), and stages 8-9 (2). During stages $3-5$, the stamens existed in the form of stamen primordia, in which anthers were undifferentiated, and no RNA was isolated at these stages. As shown in Figure 4A, a total of 4127 differentially expressed transcripts were identified in C1-a versus $\mathrm{X} 1-\mathrm{a}$, of which 2529 were up-regulated, and 1598 were down-regulated. Comparison of the C2-a and X2-a transcriptomes revealed 4517 differentially expressed transcripts, of which 2946 were up-regulated and 1571 were down-regulated. The Venn diagram shows that the expression levels of 2592 transcripts differ only at stages 6-7. A total of 2982 transcripts just had differences at stages 8-9, and 1535 transcripts showed differences in stages 6-7 and 8-9 (Figure 4B). The FPKM values of these above differentially expressed transcripts are represented in Supplementary Table S1. To characterize the functions of the differentially expressed transcripts, functional enrichment analysis was performed. The top $20 \mathrm{GO}$ terms of the differentially expressed transcripts between the male and female anthers are presented. The GO terms for the meiotic process were significantly enriched (Figure $4 \mathrm{C}$, D). Seven differentially expressed transcripts related to the meiotic process were highly expressed in female or male flowers (Figure 4E). Six transcripts homologous to the ML5 
(MEI2-like protein 5) gene had been studied in many species, suggesting it plays a key role in meiosis regulation [28,29]. One differentially expressed transcript for the kinesin-like protein, homologous to TES in Arabidopsis thaliana, presented higher expression in the male anther. It has been suggested that the TES gene promotes cytoplasmic division [30].

A

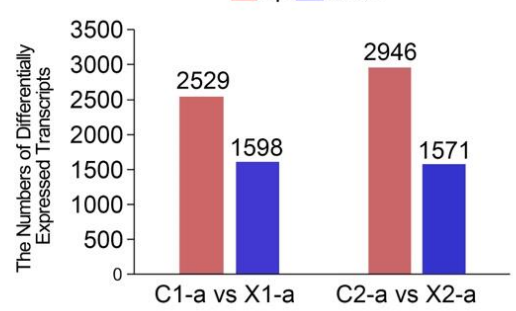

C

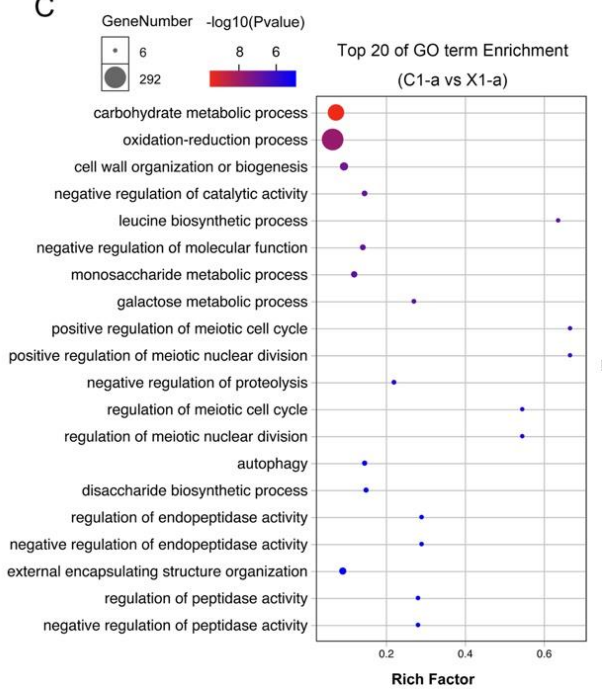

B

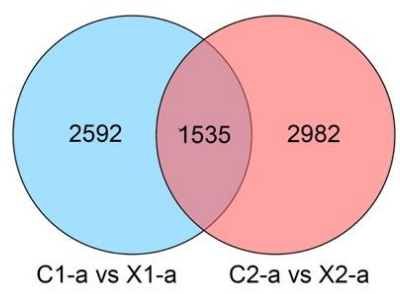

D

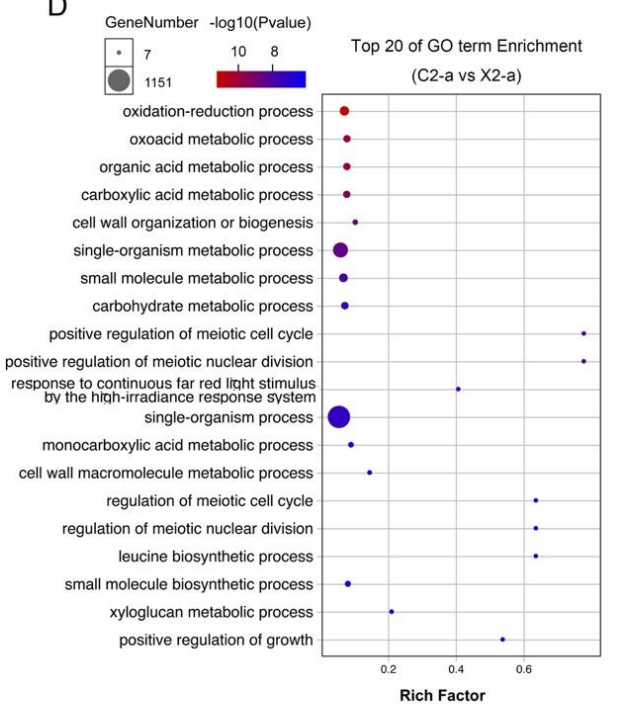

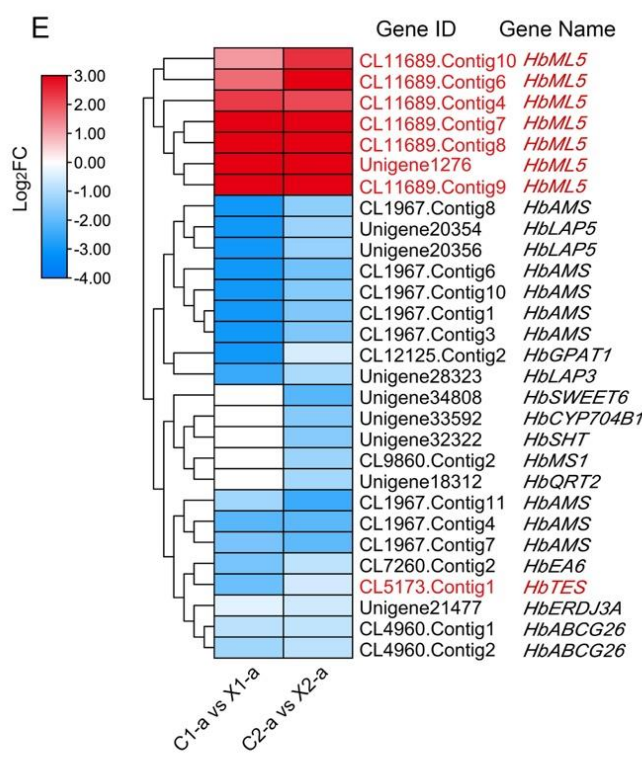

Figure 4. Analysis of the differentially expressed transcripts between male and female floral anthers. (A,B) Numbers of the differentially expressed transcripts in anthers transcriptome of male and female flowers. (C,D) GO functional enrichment of the differentially expressed transcripts in anthers' transcriptome of male and female flowers; $-\log _{10}$ Pvalue is depicted by color range from blue (low significance) to red (high significance), Rich factor refers to the ratio of the number of differentially expressed genes among the total number of genes in this term. The greater the Rich factor, the higher enrichment degree. (E) log2-transformed fold change $(\log 2 \mathrm{FC})$ values are depicted by color range from blue (down-regulated) to red (up-regulated). Slashes represent pairwise comparisons between two samples. Bar plots show the value. 
Compared with male flower stamens, the expression of $H b G P A T$, HbAMS, HbLAP5, HbLAP3, HbMS1, HbCYP704B1, HbSWEET6, HbSHT, HdQRT2, HdABCG26, HdEA6, and $H d E R D J 3 A$ were down-regulated in female flower stamens (Figure $4 \mathrm{E}$ ).

Phenotypic observation shows that the abortion of the female flower stamen occurred at stages 6-7 of anther development. HbGPAT, HbAMS, HbLAP5, and HbLAP3, all linked to anther development, were changed since stages 6-7. The stamen transcriptome results revealed that the changes in the expression level of the above four genes in the anther transcriptome correspond with changes in the flower transcriptome. Moreover, further analysis found that two meiosis-related genes, HbTES and HbML5, had abnormal expression levels at stages 6-7 during anther development in female anthers compared with male anthers.

\section{Discussion}

Handeliodendron bodinieri is the first-class national wild conservative plant and endangered tree species in China. Since it has a unisexual flower with aborted stamen or pistil in dioecious trees, it can be used as perfect material to study flower sex differentiation and unisexual flower development in tree species. This study revealed that female flower stamens began to abort at stage 6 during anther development in H. bodinieri. The stamen abortions were accompanied by abnormal development of tapetum and the unsuccessful meiosis process of MMC. Transcriptomic analysis of floral buds and stamens revealed that 14 genes had abnormal expression levels in female flowers compared to male flowers, suggesting their role in regulating anther development in male flowers in $H$. bodinieri (Figure 5). The results suggest that in $H$. bodinieri female flowers, down-regulated $H b G P A T$, HbAMS, HbLAP5, and HbLAP3 during stages 6-7 might be the main reason for abnormal MMC and anther wall tapetum differentiation. The aberrant expression of HdMEI2 and HdTES was the major reason for failed MMC meiosis, which led to the failure of tetrad formation during stamen abortion, and finally led to stamen abortion. This study about the sex differentiation of $H$. bodinieri has a high reference value for studying biomass energy plants, woody plants, and endangered plants.
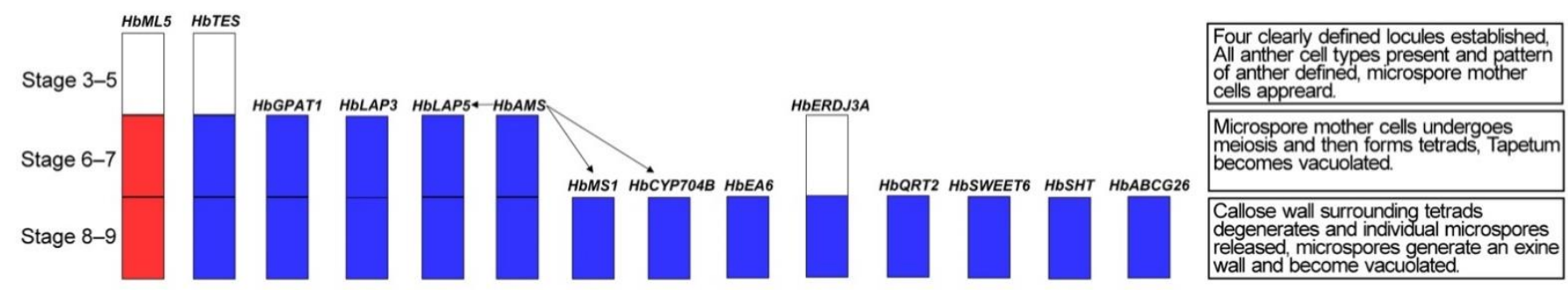

Figure 5. The expression pattern and relationship of the main 14 anther development-related or meiosis-related genes changed in female flowers. The blue boxes represent down-regulated gene expression, the red boxes represent up-regulated gene expression, and the white boxes represent insignificant changes in gene expression. The arrows show relationships between genes that have been known from previous studies.

Male sterility is more common in different species, and it had been found in a variety of plants. There are fewer abnormalities in the early stages of anther development (stages 1-3 [8]). For example, the hau CMS (hau cytoplasmic male sterility) line of B. napus aborts at archesporial cell differentiation stage [31]. In most types of male sterility, abortion mainly occurs during microsporogenesis and pollen maturation (stages $4-8$ and stages 9-14 [8]). B. napus male-sterile floral buds show that the anthers were filled with numerous highly vacuolated cells in stage 4 , and the locks with pollen sacs did not produce normal tetrads [32]. In the Tung tree (Vernicia fordii), the stamen of the male-sterile line stopped growth at early MMC stage (stages 5-6 [8]), with tapetum cell degeneration and large vacuoles in MMC [33]. In the anthers of Raphanus sativus with Ogura Male Sterile Cytoplasm, the pollen of 'MS-G' began to abort when the anthers were at the tetrad stage (stage 7 [8]) or later [34]. By contrast, Heng et al. found that the abortive stage of anther development in the oxa CMS (oxa cytoplasmic male sterility) line in B. juncea was initiated 
at the late uninucleate stage (stage 11-14 [8]), causing total male sterility when mature pollen grains release from the anther [35]. The semi-thin sections were made and observed in the anthers of $H$. bodinieri female and male flowers at continuous development stages. Abnormal formation of the tapetum was the first sign of abortion at stage 6 of anther development. The tapetum in this stage showed enhanced vacuolization, followed by a failed meiosis of the microspore mother cells. These phenotypes are consistent with the cytological observation of anther abortion in the Tung tree, where it has been suggested that the abortion of stamens in female flowers is a type of programmed cell death (PCD) caused by tapetum degeneration at the microspore mother cell stage [33].

Comparison of the $\mathrm{C}-\mathrm{a}$ and $\mathrm{X}$-a transcriptomes reveals that DEGs' functions with high "Rich Factor" were meiosis-related processes. The phenotype also shows that the meiosis of MMCs failed to normally proceed, which means that the abnormal expression of genes, especially $H b M L 5$, prevented meiosis during the anther development in female flowers. In Schizosaccharomyces pombe, Mei2 (homologous to HbML5) is considered a master regulator of meiosis and is required for pre-meiotic DNA synthesis and entry into meiosis [29]. At the same time, analyses of mutants of the maize mei2-like gene (homologous genes of HbML5), terminal ear1 (te1), do not indicate any type of meiotic defects, and te1 transcripts are expressed in shoot and root meristems rather than cells that are undergoing meiosis [36]. The Arabidopsis-Mei2-Like genes ( $A M L$, homologous for HbML5) comprise a five-member gene family. Kaur et al. revealed the role of the $A M L$ genes in meiosis, with RNAi lines and specific multiple mutant combinations displaying sterility and a range of defects in meiotic chromosome behavior [28]. On the contrary, HbML5 in H. bodinieri were abundantly expressed in the anthers of female flowers, followed by the obstruction of the meiotic process of the microspore mother cells at stage 6, and resulted in failure to form tetrads, which may suggest evolutional diversity in different species. Alternatively, as long as HbML5 expresses abnormally, the meiosis process of MMCs will be inhibited in H. bodinieri.

\section{Conclusions}

The stamen abortions in the female flowers of $H$. bodinieri were found to begin at stage 6 during anther development, and they were accompanied by abnormal development of tapetum and the unsuccessful meiosis process of MMCs. Transcriptomic analysis identified that 14 genes were related to abnormal anther development and meiosis. In $H$. bodinieri female flowers, the misexpression of HbGPAT, HbAMS, HbLAP5, and HbLAP3 could be the main reason for abnormal MMCs and anther wall tapetum differentiation, while the misexpression of HdMEI2 and HdTES could be the major reason for failed MMCs meiosis, which led to the failure of tetrad formation and finally led to stamen abortion. This information will provide a theoretical foundation for the conservation, breeding, and scientific research of endangered plants and H. bodinieri.

Supplementary Materials: The following are available online at https://www.mdpi.com/article/10 $.3390 / \mathrm{f12081071/s1,} \mathrm{Table} \mathrm{S1:} \mathrm{List} \mathrm{of} \mathrm{transcripts} \mathrm{significantly} \mathrm{differentially} \mathrm{expressed} \mathrm{in} \mathrm{the} \mathrm{female}$ flower anthers compared to male flower anthers.

Author Contributions: H.L. (Hui Li), Z.L., H.L. (Hai Lu) and X.L., designed the experiments; X.L., T.L., C.Z., X.G. and S.G. performed the experiments and statistical analysis; X.L., H.L. (Hui Li), Z.L. and H.L. (Hai Lu) wrote the manuscript. All authors have read and agreed to the published version of the manuscript.

Funding: This research was funded by the National Natural Science Foundation of China (31560200).

Institutional Review Board Statement: Not applicable.

Informed Consent Statement: Not applicable.

Data Availability Statement: The data presented in this study are available on request from the corresponding author.

Conflicts of Interest: The authors declare no conflict of interest. 


\section{References}

1. Goldberg, R.B.; Beals, T.P.; Sanders, P.M. Another development: Basic principles and practical applications. Plant Cell 1993, 5, 1217-1229.

2. McCormick, S. Control of male gametophyte development. Plant Cell 2004, 16, S142-S153. [CrossRef]

3. Scott, R.J.; Spielman, M.; Dickinson, H.G. Stamen structure and function. Plant Cell 2004, 16, S46-S60. [CrossRef]

4. Ma, H. Molecular genetic analyses of microsporogenesis and microgametogenesis in flowering plants. Annu. Rev. Plant Biol. 2005, 56, 393-434. [CrossRef] [PubMed]

5. Wilson, Z.A.; Zhang, D.B. From Arabidopsis to rice: Pathways in pollen development. J. Exp. Bot. 2009, 60, 1479-1492. [CrossRef] [PubMed]

6. Valentin-Silva, A.; Coelho, V.P.; Ventrella, M.C.; Vieira, M.F. Timing of pollen release and stigma receptivity period of Piper vicosanum: New insights into sexual reproduction of the genus. Am. J. Bot. 2015, 102, 626-633. [CrossRef] [PubMed]

7. Smyth, D.R.; Bowman, J.L.; Meyerowitz, E.M. Early flower development in Arabidopsis. Plant Cell 1990, 2, 755-767. [PubMed]

8. Goldberg, R.B.; Sanders, P.M.; Bui, A.Q.; Weterings, K.; McIntire, K.N.; Hsu, Y.C.; Lee, P.Y.; Truong, M.T.; Beals, T.P. Anther developmental defects in Arabidopsis thaliana male-sterile mutants. Sex Plant Reprod. 1999, 11, 297-322.

9. Polowick, P.L.; Sawhney, V.K. Microsporogenesis in a normal line and in the ogu cytoplasmic male-sterile line of Brassica napus. Sex Plant Reprod. 1991, 4, 22-27. [CrossRef]

10. Li, J.; Zhang, J.; Li, H.; Niu, H.; Xu, Q.; Jiao, Z.; An, J.; Jiang, Y.; Li, Q.; Niu, J. The Major Factors Causing the Microspore Abortion of Genic Male Sterile Mutant NWMS1 in Wheat (Triticum aestivum L.). Int. J. Mol. Sci. 2019, 20, 6252. [CrossRef]

11. Wang, S.; Zhang, Y.; Fang, Z.; Zhang, Y.; Song, Q.; Hou, Z.; Sun, K.; Song, Y.; Li, Y.; Ma, D.; et al. Cytological and Proteomic Analysis of Wheat Pollen Abortion Induced by Chemical Hybridization Agent. Int. J. Mol. Sci. 2019, 20, 1615. [CrossRef]

12. Bhatnagar-Mathur, P.; Gupta, R.; Reddy, P.S.; Reddy, B.P.; Reddy, D.S.; Sameerkumar, C.V.; Saxena, R.K.; Sharma, K.K. A novel mitochondrial orf147 causes cytoplasmic male sterility in pigeonpea by modulating aberrant anther dehiscence. Plant Mol. Biol 2018, 97, 131-147. [CrossRef]

13. Cnudde, F.; Hedatale, V.; de Jong, H.; Pierson, E.S.; Rainey, D.Y.; Zabeau, M.; Weterings, K.; Gerats, T.; Peters, J.L. Changes in gene expression during male meiosis in Petunia hybrida. Chromosome Res. 2006, 14, 919-932. [CrossRef] [PubMed]

14. Chen, C.; Farmer, A.D.; Langley, R.J.; Mudge, J.; Crow, J.A.; May, G.D.; Huntley, J.; Smith, A.G.; Retzel, E.F. Meiosis-specific gene discovery in plants: RNA-Seq applied to isolated Arabidopsis male meiocytes. BMC Plant Biol. 2010, 10, 280. [CrossRef]

15. Yang, H.; Lu, P.; Wang, Y.; Ma, H. The transcriptome landscape of Arabidopsis male meiocytes from high-throughput sequencing: The complexity and evolution of the meiotic process. Plant. J. 2011, 65, 503-516. [CrossRef] [PubMed]

16. Jung, K.H.; Han, M.J.; Lee, Y.S.; Kim, Y.W.; Hwang, I.; Kim, M.J.; Kim, Y.K.; Nahm, B.H.; An, G. Rice Undeveloped Tapetum1 is a major regulator of early tapetum development. Plant Cell 2005, 17, 2705-2722. [CrossRef]

17. Zheng, Z.; Xia, Q.; Dauk, M.; Shen, W.; Selvaraj, G.; Zou, J. Arabidopsis AtGPAT1, a member of the membrane-bound glycerol-3phosphate acyltransferase gene family, is essential for tapetum differentiation and male fertility. Plant Cell 2003, 15, $1872-1887$. [CrossRef]

18. Ji, C.; Li, H.; Chen, L.; Xie, M.; Wang, F.; Chen, Y.; Liu, Y.G. A novel rice bHLH transcription factor, DTD, acts coordinately with TDR in controlling tapetum function and pollen development. Mol. Plant 2013, 6, 1715-1718. [CrossRef]

19. Cao, H.; Li, X.; Wang, Z.; Ding, M.; Sun, Y.; Dong, F.; Chen, F.; Liu, L.; Doughty, J.; Li, Y.; et al. Histone H2B Monoubiquitination Mediated by HISTONE MONOUBIQUITINATION1 and HISTONE MONOUBIQUITINATION2 Is Involved in Anther Development by Regulating Tapetum Degradation-Related Genes in Rice. Plant Physiol. 2015, 168, 1389-1405. [CrossRef] [PubMed]

20. Millar, A.A.; Gubler, F. The Arabidopsis GAMYB-like genes, MYB33 and MYB65, are microRNA-regulated genes that redundantly facilitate anther development. Plant Cell 2005, 17, 705-721. [CrossRef]

21. Fu, Z.; Yu, J.; Cheng, X.; Zong, X.; Xu, J.; Chen, M.; Li, Z.; Zhang, D.; Liang, W. The Rice Basic Helix-Loop-Helix Transcription Factor TDR INTERACTING PROTEIN2 Is a Central Switch in Early Anther Development. Plant Cell 2014, 26, $1512-1524$. [CrossRef]

22. Jeong, H.J.; Kang, J.H.; Zhao, M.; Kwon, J.K.; Choi, H.S.; Bae, J.H.; Lee, H.A.; Joung, Y.H.; Choi, D.; Kang, B.C. Tomato Male sterile 1035 is essential for pollen development and meiosis in anthers. J. Exp. Bot 2014, 65, 6693-6709. [CrossRef]

23. Cao, L.M.; Xia, N.H.; Deng, Y.F. Embryology of Handeliodendron bodinieri (Sapindaceae) and its systematic value: Development of male and female gametophytes. Plant Syst. Evol. 2008, 274, 17-23. [CrossRef]

24. Grabherr, M.G.; Haas, B.J.; Yassour, M.; Levin, J.Z.; Thompson, D.A.; Amit, I.; Adiconis, X.; Fan, L.; Raychowdhury, R.; Zeng, Q.; et al. Full-length transcriptome assembly from RNA-Seq data without a reference genome. Nat. Biotechnol. 2011, $29,644-652$. [CrossRef]

25. Pertea, G.; Huang, X.; Liang, F.; Antonescu, V.; Sultana, R.; Karamycheva, S.; Lee, Y.; White, J.; Cheung, F.; Parvizi, B.; et al. TIGR Gene Indices clustering tools (TGICL): A software system for fast clustering of large EST datasets. Bioinformatics 2003, 19, 651-652. [CrossRef] [PubMed]

26. Conesa, A.; Gotz, S.; Garcia-Gomez, J.M.; Terol, J.; Talon, M.; Robles, M. Blast2GO: A universal tool for annotation, visualization and analysis in functional genomics research. Bioinformatics 2005, 21, 3674-3676. [CrossRef] [PubMed]

27. Chen, C.; Chen, H.; Zhang, Y.; Thomas, H.R.; Frank, M.H.; He, Y.; Xia, R. TBtools: An Integrative Toolkit Developed for Interactive Analyses of Big Biological Data. Mol. Plant 2020, 13, 1194-1202. [CrossRef] [PubMed] 
28. Kaur, J.; Sebastian, J.; Siddiqi, I. The Arabidopsis-mei2-like genes play a role in meiosis and vegetative growth in Arabidopsis. Plant Cell 2006, 18, 545-559. [CrossRef] [PubMed]

29. Watanabe, Y.; Yamamoto, M.S. pombe mei2+ encodes an RNA-binding protein essential for premeiotic DNA synthesis and meiosis I, which cooperates with a novel RNA species meiRNA. Cell 1994, 78, 487-498. [CrossRef]

30. Tanaka, H.; Ishikawa, M.; Kitamura, S.; Takahashi, Y.; Soyano, T.; Machida, C.; Machida, Y. The AtNACK1/HINKEL and STUD/TETRASPORE/AtNACK2 genes, which encode functionally redundant kinesins, are essential for cytokinesis in Arabidopsis. Genes Cells 2004, 9, 1199-1211. [CrossRef] [PubMed]

31. Heng, S.; Chen, F.; Wei, C.; Li, X.; Yi, B.; Ma, C.; Tu, J.; Shen, J.; Fu, T.; Wen, J. Cytological and iTRAQ-based quantitative proteomic analyses of hau CMS in Brassica napus L. J. Proteom. 2019, 193, 230-238. [CrossRef]

32. An, H.; Yang, Z.; Yi, B.; Wen, J.; Shen, J.; Tu, J.; Ma, C.; Fu, T. Comparative transcript profiling of the fertile and sterile flower buds of pol CMS in B. napus. BMC Genom. 2014, 15, 258. [CrossRef] [PubMed]

33. Liu, M.; Li, W.; Zhao, G.; Fan, X.; Long, H.; Fan, Y.; Shi, M.; Tan, X.; Zhang, L. New Insights of Salicylic Acid into Stamen Abortion of Female Flowers in Tung Tree (Vernicia fordii). Front. Genet. 2019, 10, 316. [CrossRef] [PubMed]

34. Yang, S.; Terachi, T.; Yamagishi, H. Inhibition of chalcone synthase expression in anthers of Raphanus sativus with Ogura male sterile cytoplasm. Ann. Bot. 2008, 102, 483-489. [CrossRef] [PubMed]

35. Heng, S.; Liu, S.; Xia, C.; Tang, H.; Xie, F.; Fu, T.; Wan, Z. Morphological and genetic characterization of a new cytoplasmic male sterility system (oxa CMS) in stem mustard (Brassica juncea). Theor. Appl. Genet. 2018, 131, 59-66. [CrossRef] [PubMed]

36. Veit, B.; Briggs, S.P.; Schmidt, R.J.; Yanofsky, M.F.; Hake, S. Regulation of leaf initiation by the terminal ear 1 gene of maize. Nature 1998, 393, 166-168. [CrossRef] 